ECCOMAS

\section{Proceedia}

COMPDYN 2021

$8^{\text {th }}$ ECCOMAS Thematic Conference on Computational Methods in Structural Dynamics and Earthquake Engineering

M. Papadrakakis, M. Fragiadakis (eds.)

\title{
FINITE ELEMENT ANALYSIS OF JUMA MOSQUE IN UZBEKISTAN BASED ON LASER SCANNING AND AMBIENT STUDIES
}

\author{
Shakhzod M. Takhirov ${ }^{1}$ and Bakhodir S. Rakhmonov ${ }^{2}$ \\ ${ }^{1}$ Structures Laboratory, Civil and Environmental Engineering Department, University of California, \\ Berkeley \\ 337 Davis Hall, Berkeley, CA 94720, USA \\ takhirov@berkeley.edu \\ ${ }^{2}$ Construction and Architecture Department, Urgench State University \\ 14, Khamid Olimjon Str., Urgench, 220100, Uzbekistan \\ rah-bahodir@yandex.com
}

\begin{abstract}
This paper highlights the main objectives and some of the results of an extensive structural health monitoring (SHM) project recently started in Khiva, Uzbekistan. The research team consisted of experts from the University of California, Berkeley (Berkeley, USA) and Urgench State University (Urgench, Uzbekistan). The paper presents results for the Juma Mosque in Itchan Kala. The structural health monitoring project was planned as a comprehensive study consisting of three major phases. In Phase 1, a terrestrial laser scanner was deployed to capture $3 D$ geometry and identify anomalies in the monument's geometry. In this phase, the monument's geometry was captured as a collection of points, the so-called "point clouds". In Phase 2, a finite-element (FE) model based on the as-found geometry of the point clouds was generated. This model was generated to optimize placement of the conventional instruments to be used in Phase 3. A number of structural anomalies were discovered during Phase 1 and all of them are incorporated into the FE model. In Phase 3, there is a plan to monitor the monument by means of conventional instruments (accelerometers, displacement transducers, temperature gages and others). Accelerometers will be used to measure the resonant frequencies due to ambient vibrations. Displacement transducers will be used along with temperature gages to monitor the opening and closing of cracks under different thermal conditions and to measure the long-term growth trends of the cracks. The FE model will be updated based on the results of Phase 3. Preservation and restoration strategies will be developed based on the performance of the FE model under static and dynamic loads.
\end{abstract}

Keywords: Heritage Building Preservation, Laser Scanning, Finite Element Modelling, Structural Dynamics. 


\section{INTRODUCTION}

This paper presents some of the results of the ongoing structural health monitoring program being conducted in Khiva, Uzbekistan. This paper focuses on the finite element (FE) modelling of the Juma Mosque in Itchan Kala, the inner city of Khiva. The main objective of the modelling is to develop an accurate representation of the actual monument so it can be investigated for seismic loading. The geometry of the FE model is based on the 3D point cloud collected during Phase 1 of the project. The main objective of Phase 2 is to generate a FE model with some assumptions about material properties. The next phase (Phase 3) will include field studies by means of conventional instruments: accelerometers, displacement transducers and thermocouples, to name a few. Since the number of instruments is limited and the access duration to the site is tight, the locations of the instruments need to be optimized to collect valuable information with the limited resources and within a reasonable timeframe. The results of this portion of the work are discussed herein. The model will be updated later based on the results of Phase 3.

\section{GEOMETRY BASED ON POINT CLOUDS}

The results of Phase 1 were published earlier [1]. As presented in Figure 1, the heritage structure consists of a courtyard surrounded by walls and a minaret incorporated into its north wall. The courtyard is covered by a roof that is supported by numerous timber columns. The heritage structure was scanned by ScanStation C10 from Leica Geosystems [2] and the socalled registration of the point clouds was conducted in Cyclone [3], also from Leica Geosystems.

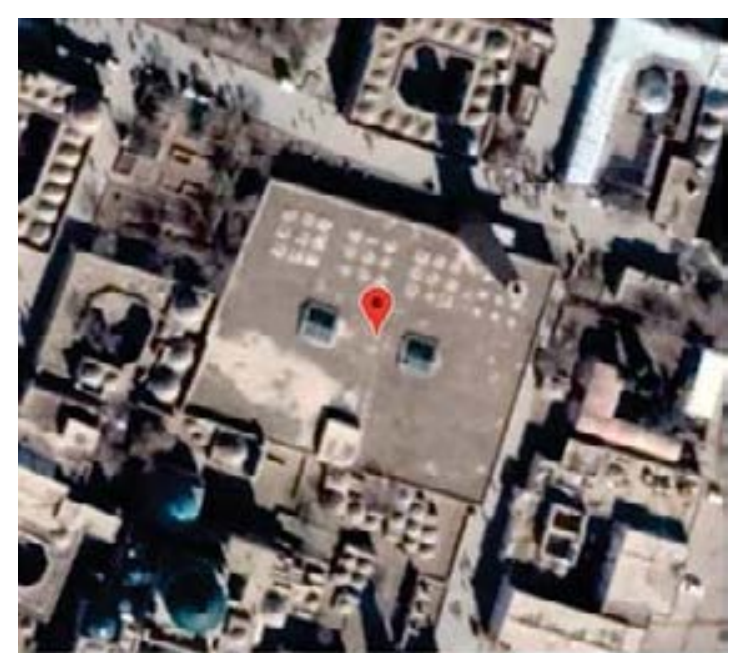

a) Aerial view from Google Maps

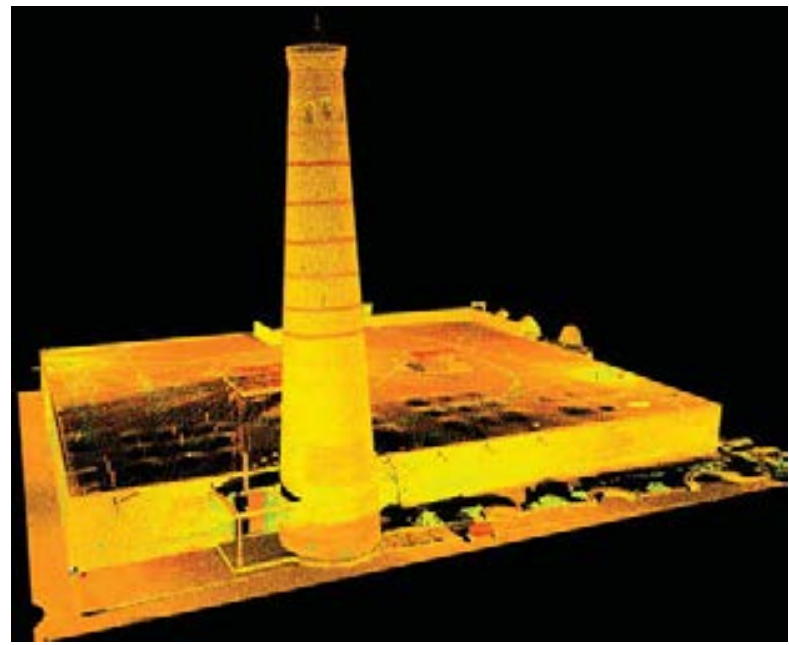

b) Point cloud

Figure 1: Juma Mosque [1].

\section{MODELLING OF MINARET}

The minaret was modelled in SAP2000 [4] by utilizing solid 3D elements and some results were published earlier [5]. In this study of the minaret the interaction of the minaret with the walls was not considered and as such, the monument was studied as a stand-alone structure as presented in Figure 2. In this paper, the minaret's model is integrated into the walls of the heritage structure. From the analysis of the point clouds, it was observed that the minaret's axis is inclined in respect to the vertical gravitational axis. This imperfection is included into the model discussed herein. 


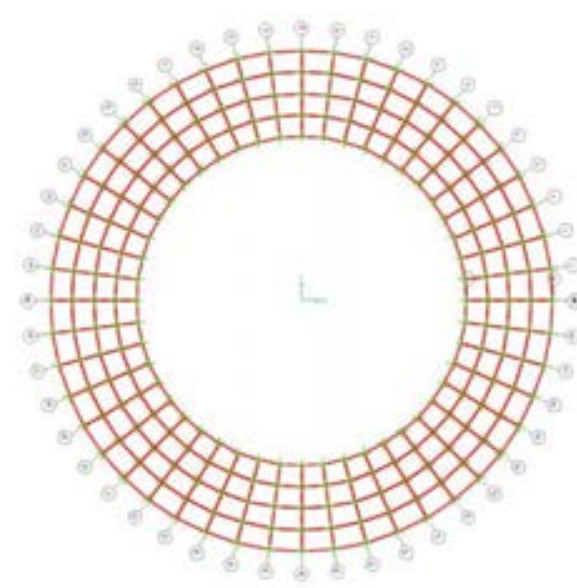

a) Bottom (left) and top (right) sections

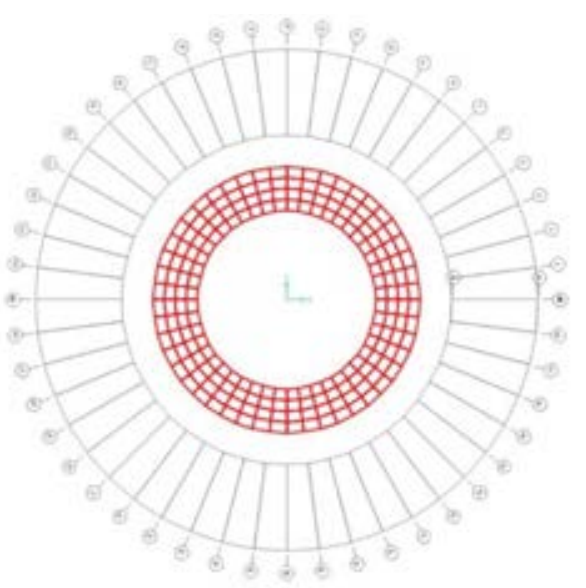

Figure 2: Model of minaret [5].

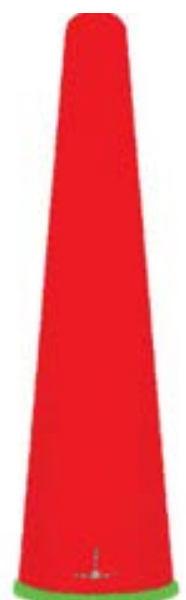

b) $3 \mathrm{D}$ mesh

\section{MODELLING OF WALLS}

The walls of the heritage structure were also modelled in SAP2000 [4] by utilizing solid 3D elements. A global view of the heritage structure with a vertical reference plane crossing the wall is presented in Figure 3a. A plane view of the typical cross section of the wall's point cloud is presented in Figure 3b. In this image, a spacing between the grid lines is $0.25 \mathrm{~m}$ and one of the vertical grid lines is selected to be parallel to the inner wall. Based on the image, the following was concluded. First, the overall height of the wall is about $5 \mathrm{~m}$ and the roof starts at about $4 \mathrm{~m}$. Second, the wall thickness at the very bottom is about $1.0 \mathrm{~m}$ and about $0.75 \mathrm{~m}$ at the roof level. Third, the outer surface of the wall has a slope in respect to a vertical line. Fourth, the inner surface of the wall is very close to vertical.

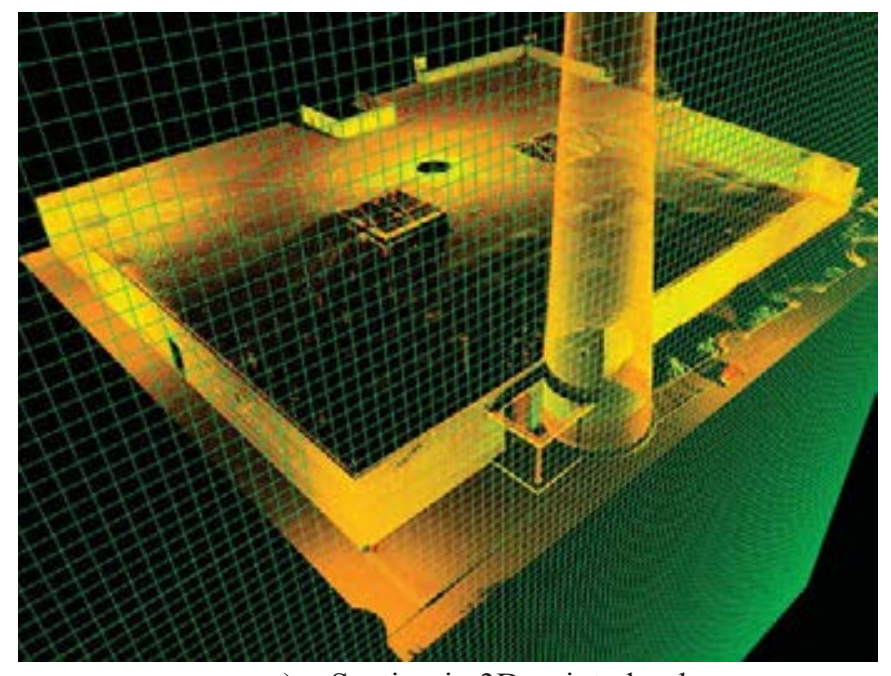

a) Section in $3 \mathrm{D}$ point cloud

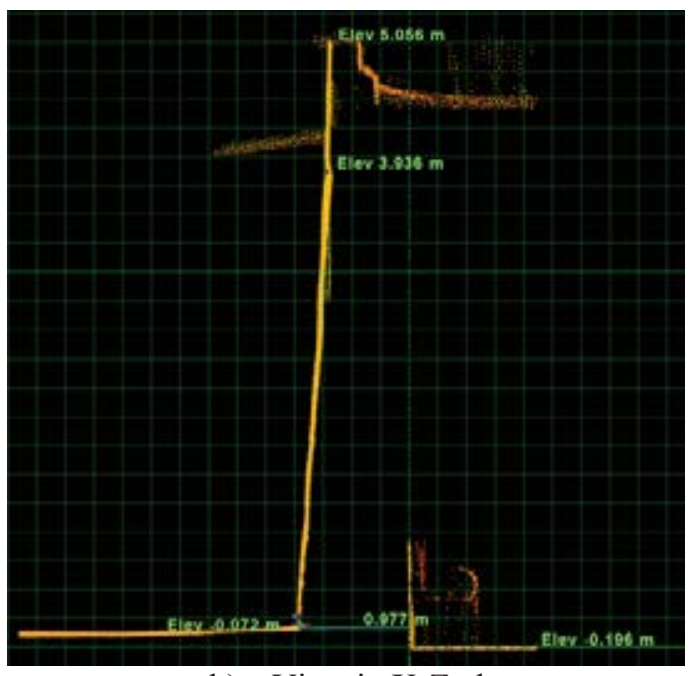

b) View in X-Z plane

Figure 3: Typical geometry of wall's cross section.

The overall length of the north wall is presented in Figure 4. A length of each wall was published earlier [1] and the corner locations are shown in Figure 5. All of this information was used in the generation of the FE model. 


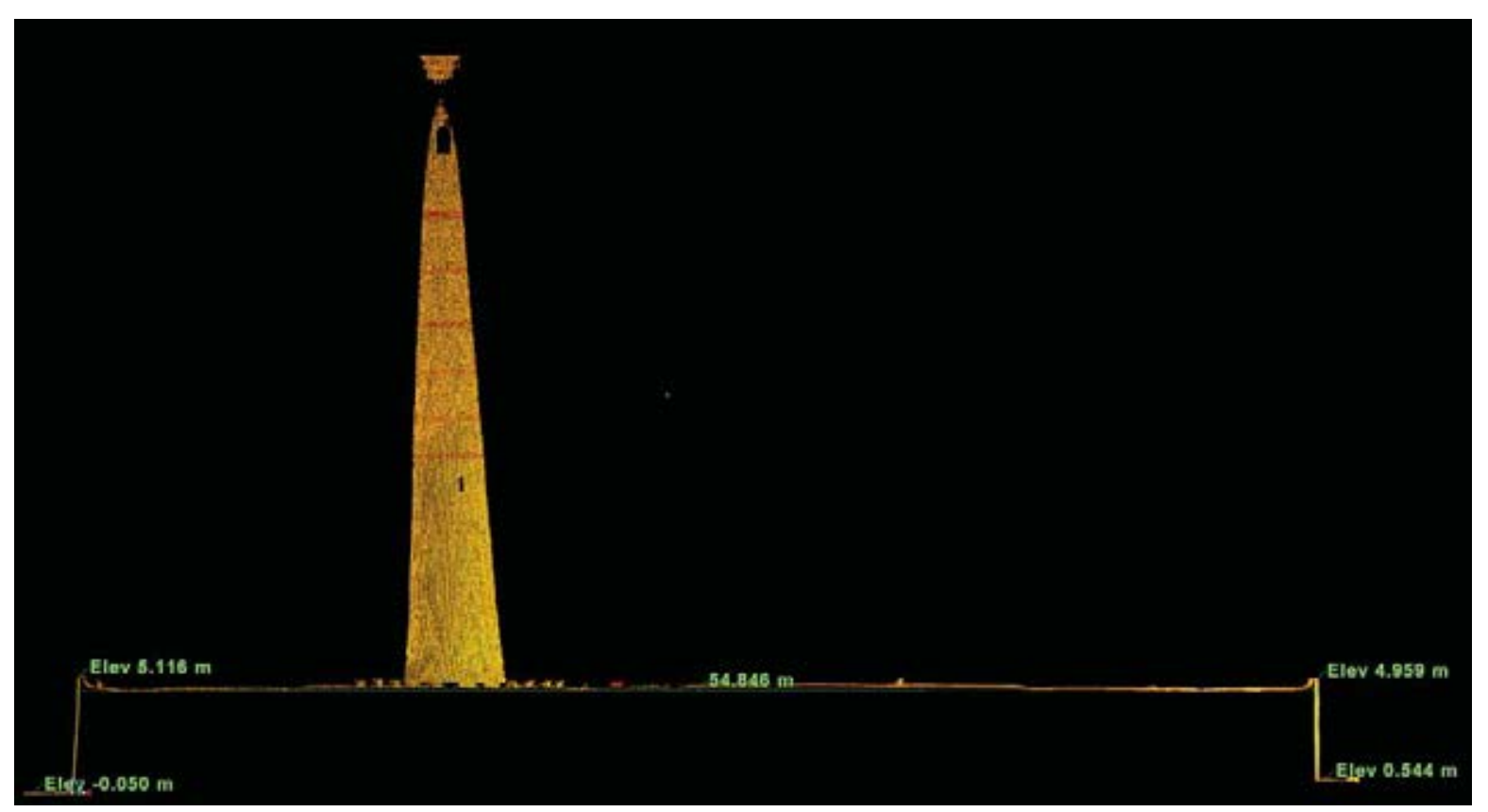

Figure 4: Overall length of north wall.

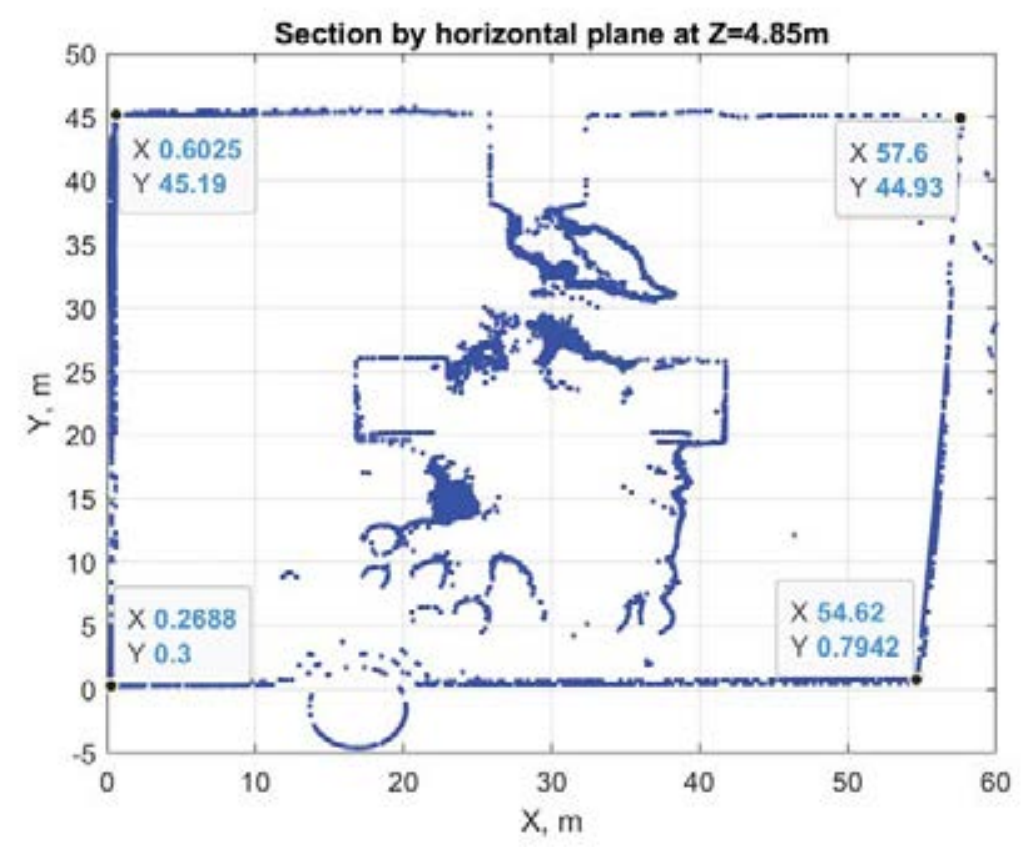

Figure 5: Plan view at $Z=4.85 \mathrm{~m}$ : corner locations.

The openings in the north and east walls shown in Figure 6 were also taken into account. The opening in the north wall right next to the minaret serves as the main entrance into the heritage structure. 


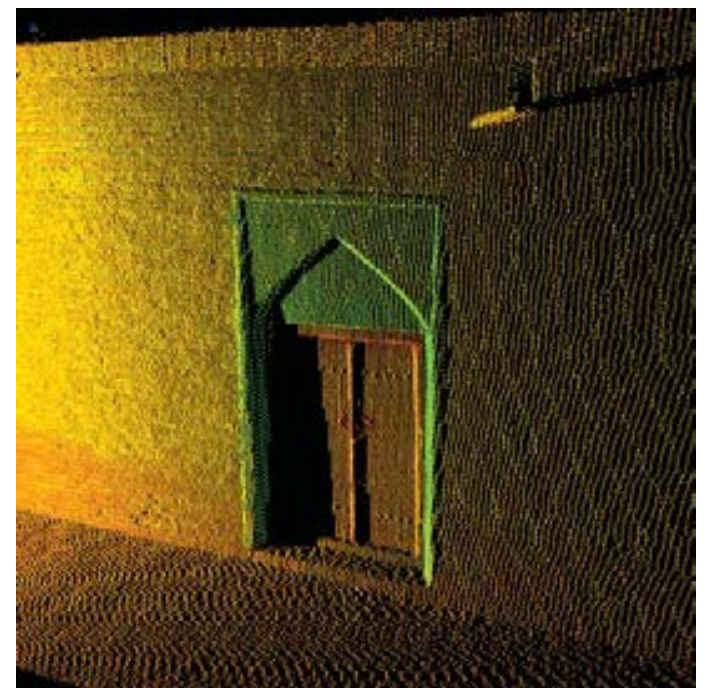

a) East wall

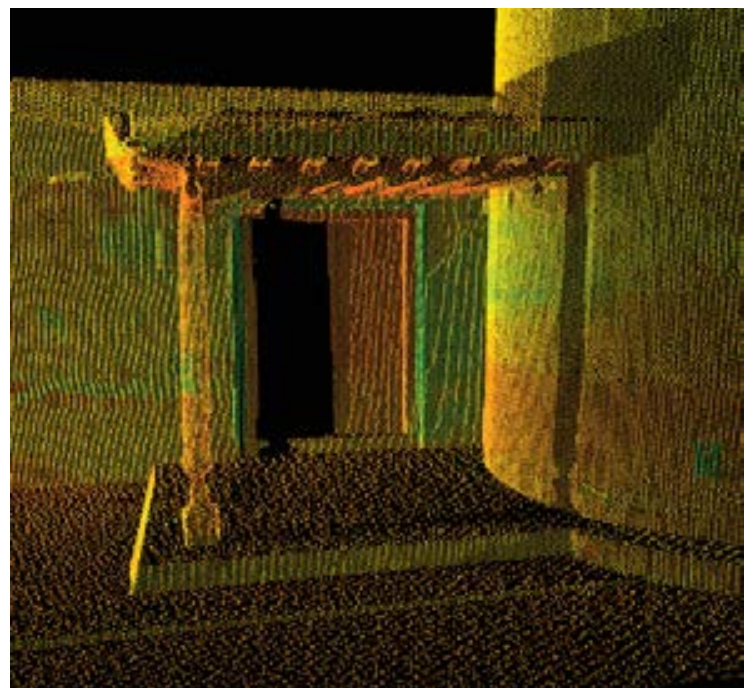

b) North wall

Figure 6: Wall openings.

\section{MODELLING OF ROOF DIAPHRAGM}

The roof diaphragm was modelled by shell elements in SAP2000. Based on the measurements of the point clouds, the spacing between the columns was very close to $3 \mathrm{~m}$ as presented in Figure 7a. A typical view inside of the courtyard is presented in Figure 7b. A proper selection of the boundary conditions closely replicating the support columns is very important to ensure that the model closely represents the heritage structure. In the majority of cases the column has a narrow end at its bottom, which is installed into a stone or concrete footing as presented in Figure 8a. The interface between the narrow end and the concrete or stone is packed with a soft material as presented in Figure 8b. Therefore, it was assumed that the columns are free to rock and as such, roller type boundary conditions were assumed under the roof diaphragm at the locations of the columns.

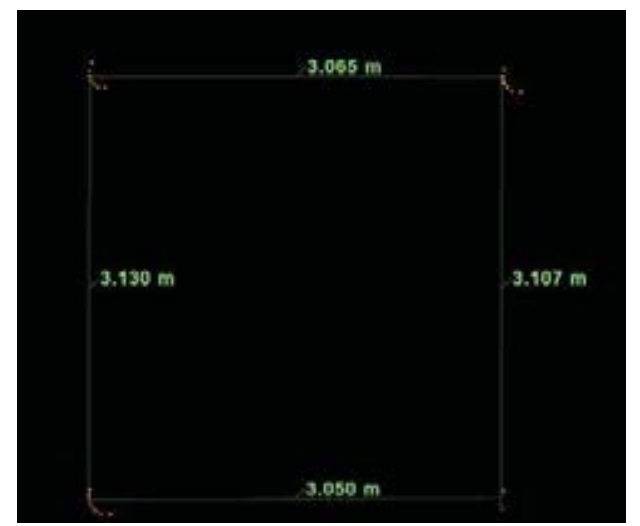

a) Spacing between columns

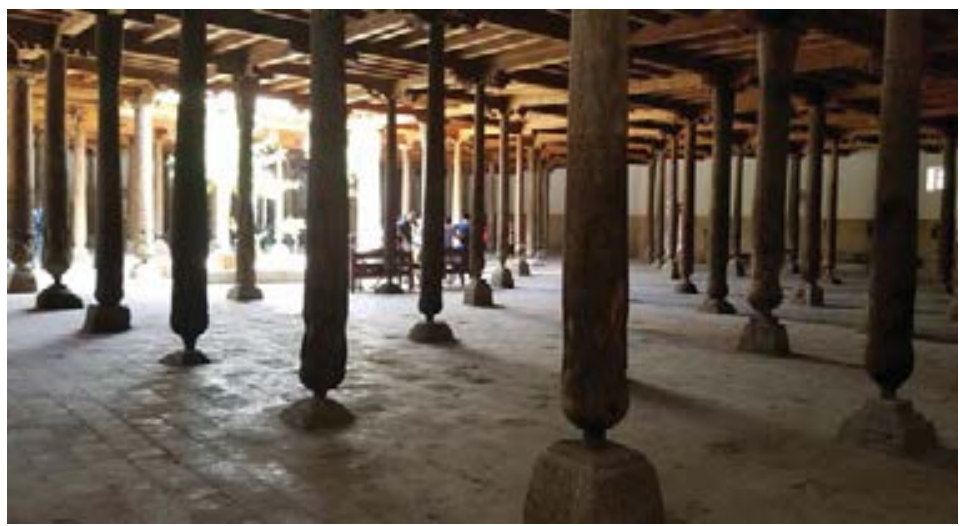

b) Typical inside view in the courtyard

Figure 7: Support columns. 


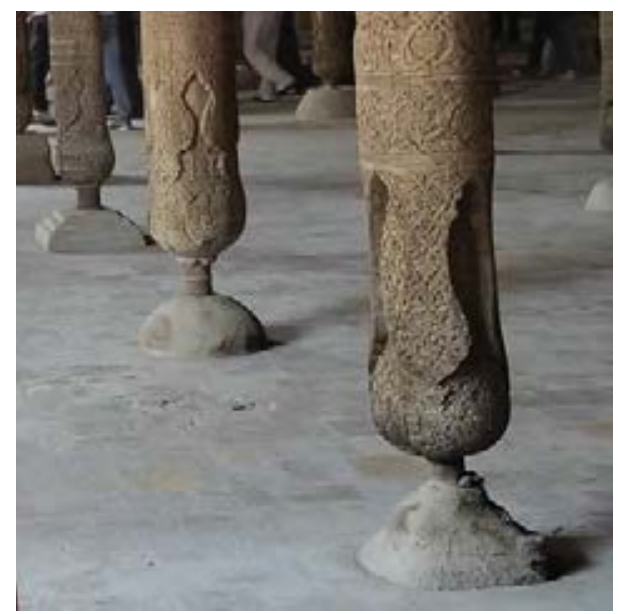

a) Typical layout of columns

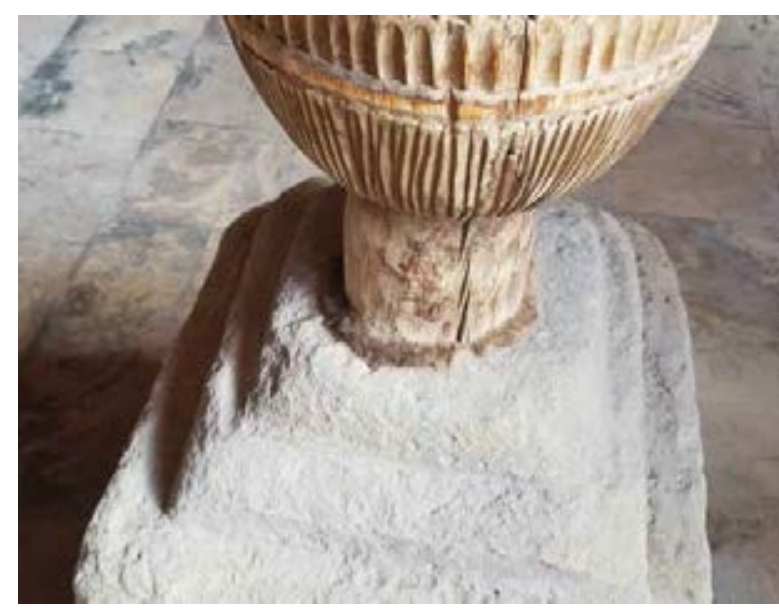

b) Boundary conditions at bottom of columns

Figure 8: Support columns: details.

There are two skylights in the roof as presented in Figure 9. They were also introduced into the roof model as openings in the diaphragm.

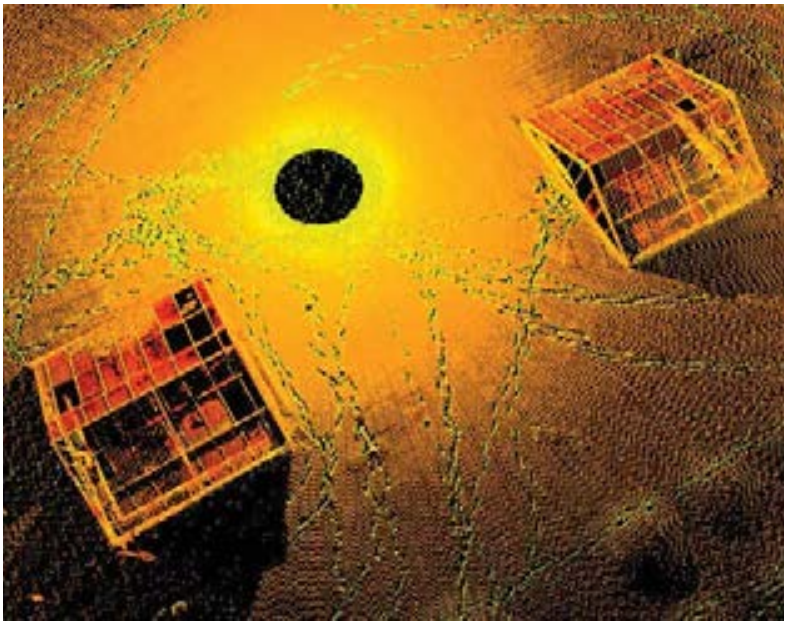

a) Two skylights

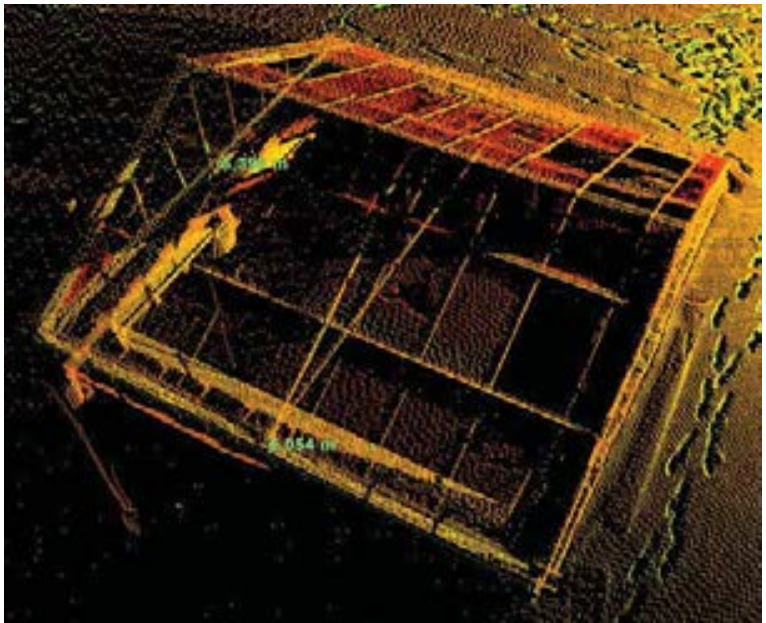

b) Typical dimensions

Figure 9: Skylights in roof diaphragm.

\section{FINITE ELEMENT MODEL}

A final model of the heritage structure that consists of the walls, minaret and roof diaphragm is presented in Figure 10a. It was assumed that there is a rigid connection between these major components of the model. A modal analysis was performed. A typical result showing the first modal shape is presented in Figure 10b. The first modal shape is associated with the first flexural vibration mode of the minaret.

The second mode was also associated with the first flexural mode of the conical body in a horizontal plane orthogonal to the one of the first mode as presented in Figure 11a. The third mode was also associated with the minaret's vibrational mode and corresponded to a second mode of the conical body as presented in Figure $11 \mathrm{~b}$.

The fifth modal shape was associated with the minaret and represented the tortional mode of the vibrations of the conical body. The modal shapes 6,7 , and 8 corresponded to the higher modes of the minaret. Only starting from mode 9 a vibration mode of the walls was observed 
as presented in Figure 12a. The modal shape of the east and west walls are shown in Figure $12 b$.

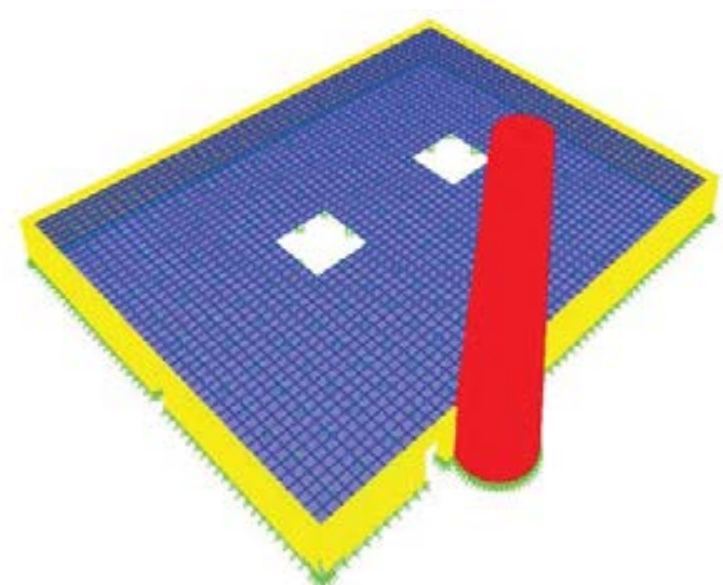

a) FE model

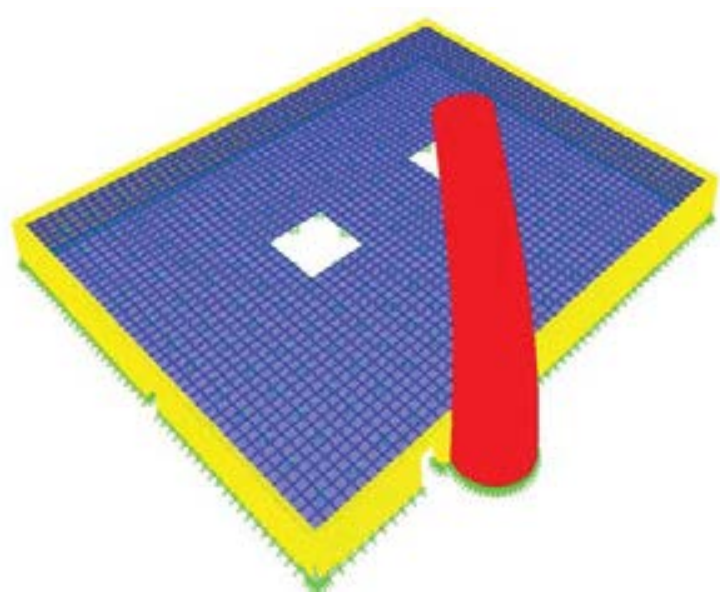

b) $1^{\text {st }}$ modal shape

Figure 10: FE model and $1^{\text {st }}$ modal shape.

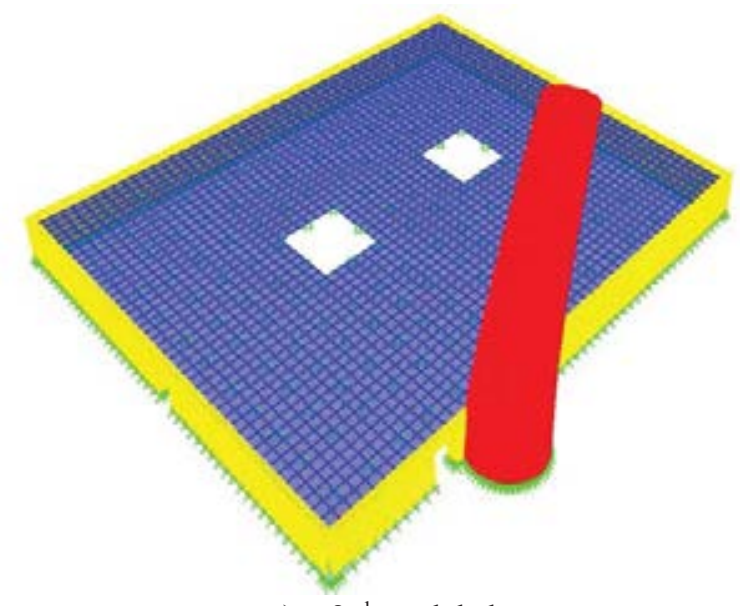

a) $2^{\text {nd }}$ modal shape

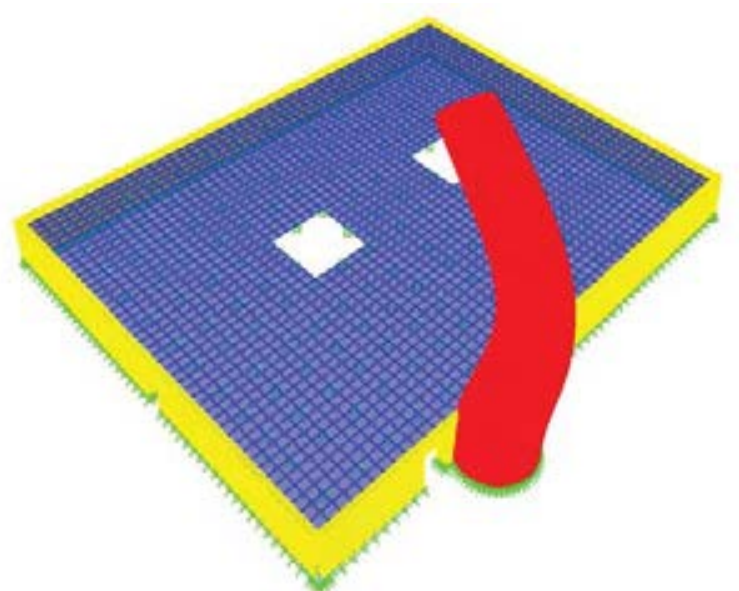

b) $3^{\text {rd }}$ modal shape

Figure 11: Typical results of modal analysis: minaret modes.

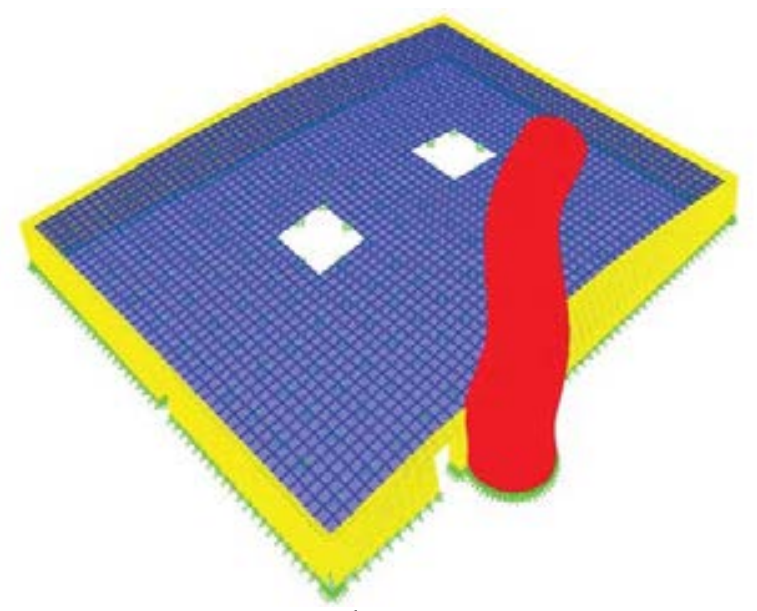

a) $9^{\text {th }}$ modal shape

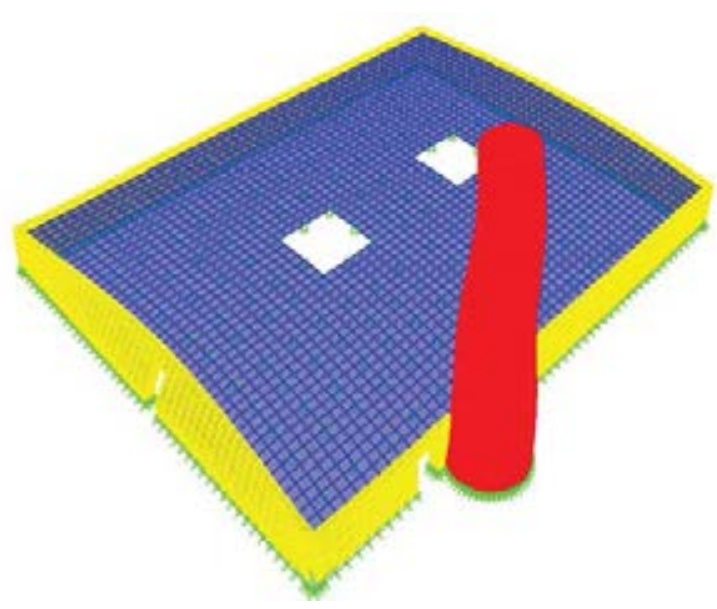

b) $11^{\text {th }}$ modal shape

Figure 12: Typical results of modal analysis: wall modes. 
Estimates of the following frequencies were obtained for the assumed material properties. The first resonant frequency of the minaret is about $2.2 \mathrm{~Hz}$. The estimates of the resonant frequencies of the walls were greater than $20 \mathrm{~Hz}$. The resonant frequency of the roof is greater than $27 \mathrm{~Hz}$. To capture the first three modes of the minaret the accelerometers in Phase 3 will be installed at the elevations shown in Figure 13.

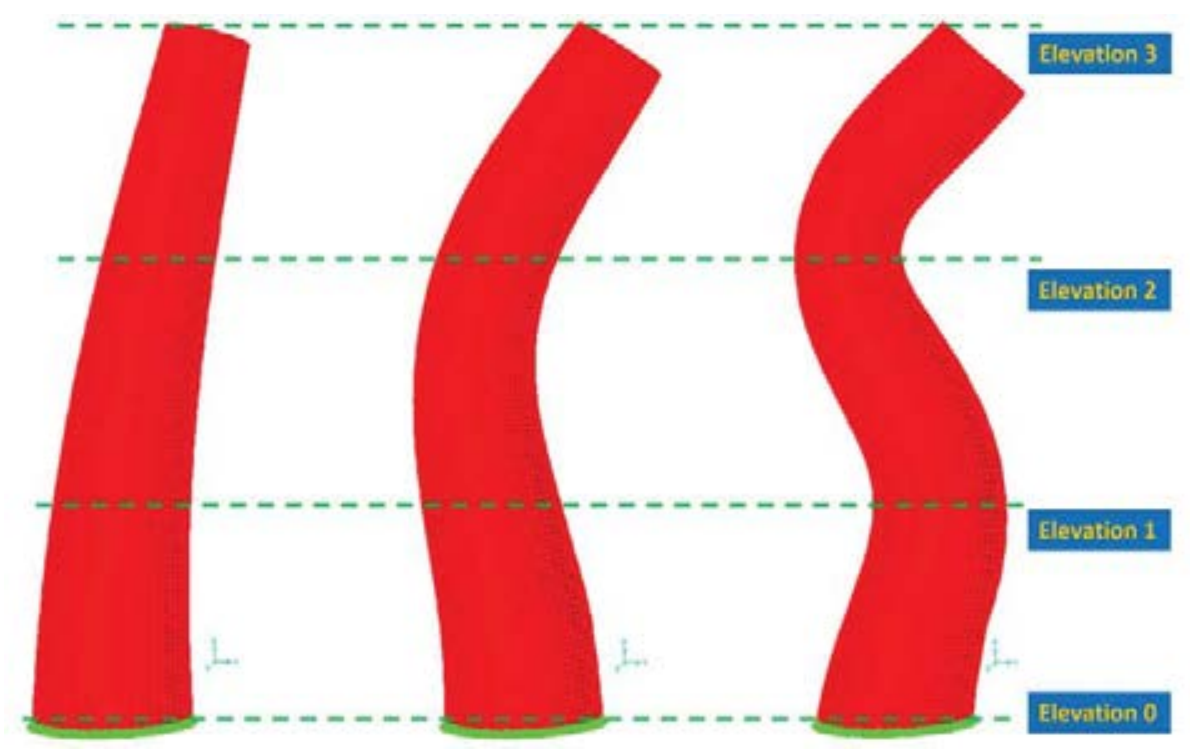

Figure 11: Typical results of modal analysis: wall modes.

To capture the torsional mode of the minaret the accelerometers will be installed at diametrically opposite locations of Elevation 0 and Elevation 3.

\section{CONCLUSIONS}

A detailed finite element model of the Juma Mosque in Uzbekistan was generated. The geometry of the heritage structure was obtained from the point clouds captured by a laser scanner. Typical material properties for brick masonry and timber were assumed. The modal analysis of the FE revealed the following.

- The first eight resonant frequencies of the heritage structure are associated with various flexural modes of the minaret.

- The wall frequencies are greater than $20 \mathrm{~Hz}$.

- The roof frequency is greater than $27 \mathrm{~Hz}$.

- A placement of accelerometers in the upcoming Phase 3 of the project was optimized based on the analysis of modal shapes. The FE model will be updated after ambient vibration studies of the heritage structure which is the main objective of Phase 3.

\section{ACKNOWLEDGMENTS}

The project would not be possible without funding provided by the Central Asia University Partnerships Program (UniCEN). UniCEN is sponsored by the U.S. Embassy in Tashkent, Uzbekistan and administered by the American Councils for International Education. Special thanks are due to Mr. Brian Quigley of BNZ, Uzbekistan for providing access to a terrestrial laser scanner. The authors would like to acknowledge the Delta Group Max, Uzbekistan for logistical and technical support provided for the laser scanning project. The authors also 
would like to acknowledge a large group of faculty and students of Urgench State University, Uzbekistan for active participation in this multi-phase project. Special thanks are due to Holly Halligan of UC Berkeley for editing the paper.

\section{REFERENCES}

[1] Shakhzod Takhirov, Bakhodir Rakhmonov, Ravshanbek Nafasov, Abbos Samandarov, Sevara Sultanova, Javlon Musurmanov, Bakhtiyor Takhirov (2021). Structural Health Monitoring of Juma Mosque in Itchan Kala, Uzbekistan by Laser Scanning. 10th International Conference on Structural Health Monitoring of Intelligent Infrastructure. 30 June - 2 July, 2021, Porto, Portugal.

[2] Leica Geosystems AG (2011). Leica ScanStation C10. https://w3.leicageosystems.com/downloads123/hds/hds/ScanStation $\% 20 \mathrm{C} 10 /$ brochuresdatasheet/Leica_ScanStation_C10_DS_en.pdf.

[3] Leica Geosystems (2018). Cyclone Version 9.2.1.

[4] Computers and Structures, Inc., CSI (2014): SAP2000 Ultimate Version 16.1.1. Structural Analysis Program.

[5] Shakhzod M. Takhirov and Bakhodir Rakhmonov (2020). Structural Health Monitoring of the Juma Mosque in Itchan Kala in Khiva (Uzbekistan): Laser Scanning Combined with Numerical Modelling. 12th International Conference on Structural Analysis of Historical Constructions, SAHC 2020, P. Roca, L. Pelà and C. Molins (Eds.) 